\title{
Synthesis and Structural Studies of $\left(\eta^{3}\right.$-allyl)carbonylnitrosyl Triphenylphosphine Iron Complexes
}

\begin{abstract}
MISBAH TABASSAM ${ }^{1}$, MUHAMMAD IMRAN ${ }^{1 *}$, AMNA FARO0Q ${ }^{1}$, SYEDA ROBINA GILLANI ${ }^{2}$, ZAID MEHMOOD ${ }^{1}$, ASAD GULZAR ${ }^{3}$, LIVIU MITU4*

${ }^{1}$ Institute of Chemistry, University of the Punjab, Lahore, Pakistan

2Department of Chemistry, University of Engineering and Technology, Lahore, Pakistan

${ }^{3}$ Department of Chemistry, University of Education, Township Campus, Lahore, Pakistan

${ }^{4}$ University of Pitesti, Department of Nature Sciences, 1 Targu din Vale Str., 110040, Pitesti, Romania

In this paper we report the preparation of two $\left(\eta^{3}\right.$-allyl)carbonylnitrosyltriphenylphosphine iron complexes i.e. $(\pi$-allyl)carbonylnitrosyltriphenylphosphine iron (1) and (2-methyl- $\pi$-allyl) carbonylnit rosyltriphenylphosphine iron (2). These complexes (1) and (2) were prepared by reacting $(\pi-$ allyl) dicarbonylnitrosyl iron and (2-methyl- $\pi$-allyl) dicarbonylnitrosyl iron with triphenylphosphine under inert atmospheric conditions. Both the resulting complexes were sufficiently and well characterized by $I R,{ }^{1} H$ $N M R,{ }^{13} \mathrm{C} N M R, E S I / M S, H R M S$ and single crystal XRD. Triphenylphosphine ligand was found to be strong sigma donor and replaced carbonyl ligand readily. XRD revealed that the geometry of iron in both complexes is distorted octahedral.
\end{abstract}

Keywords: Iron, triphenylphosphine, allyl complexes

The allyl ligand is of great interest and has been widely used in several synthesis and transition metal mediated reactions [1]. Iron allyl complexes have been reported previously as versatile intermediate in organic synthesis [2-4]. Catalysis based on such metal complexes has been recognized as pow erful synthetic tool in organic synthesis [5]. This is because in such transition metal allyl complexes, metal-ligand bond is generally weaker than normal covalentbond. Moreover, due to variable oxidation state property of transition metal, there is a unique possibility of switching reversibly between different oxidation states by redox reactions. It is well established in the literature that $\eta^{3}$-allyl iron can be synthesized from many organic compounds and possess amphiphilic reactivities with high regio and stereoselectivity [6, 7]. ( $\eta^{3}$-allyl)dicarbonylnitrosyl iron complexes possess very rich structural features and characteristics. For instance, these complexes exhibit endo-exo and syn-anti isomerism as well as planar chirality of allyl ligands. Their other challenging characteristics include metal center chirality due to the pseudo tetrahedral coordination of the iron atom by four different ligands [8]. In 1974, Cardaci reported some findings about the effect of different substituent on allyl moiety on the structure of $\left(\pi\right.$-allyl) $\mathrm{Fe}(\mathrm{CO})_{2}(\mathrm{NO})$ and their phosphine derivatives [9] . We have previously also reported synthesis and detailed structural studies of $\left[\left(\eta^{3}\right.\right.$-allyl) $\mathrm{Fe}(\mathrm{CO})$ ( $\left.\left.\mathrm{NO}\right)\right]$ using tetrabutylammonium ferrate and several allyl substrates such as allyl chloride and ally bromides [10]. In this paper we report synthesis and structural aspects of two $\left(\eta^{3-}\right.$ allyl)carbonylnitrosylphosphine iron complexes. The purpose of the study was to investigate the structural and bonding aspects of these novel complexes for their possible use in catalysis. Catalytic studies are under progress and will be communicated soon.

\section{Experimental part}

Material and methods

All the reactions and necessary manipulations which are sensitive to air and moisture were performed with rigorous exclusion of air and moisture under an atmosphere of dry nitrogen by using high vacuum Schlenk techniques. All chemicals were purchased from E-Merck (Darmstadt,
Germany). Nuclear magnetic resonance (NMR) spectra were recorded with BRUCKER Avance 500 spectrometer at $500 \mathrm{MHz}\left({ }^{1} \mathrm{H} \mathrm{NMR}\right), 125.7 \mathrm{MHz}\left({ }^{13} \mathrm{C} \mathrm{NMR}\right)$ at ambient temperature, tetramethylsilane (TMS) as internal standard. The IR instrument used was BRUCKER Vector 22 FT-IR spectrometer. Low resolution mass spectrometry (LRMS) and High resolution mass spectrometry (HRMS) of the allyl iron complexes was done using BRUCKER Type microTOF-Q (ESI). Crystal structure of the complexes were determined by NICOLEF P3 four-cycle diffractometer (Eulerian cradle), measurement method used was Wyckoff SCAN. X-ray crystallographic data/parameters for compounds (1) and (2) have been given in (table 1 ).

\section{Preparation of $(\pi$-allyl)carbonylnitrosyltriphenyl-phosphine iron (1).}

A mixture of $(\pi$-allyl) dicarbonylnitrosyl iron complex $(0.367 \mathrm{~g}, 2.0 \mathrm{mmol})$ and triphenylphosphine $(0.524 \mathrm{~g}, 2.0$ $\mathrm{mmol}$ ) was stirred in $20 \mathrm{~mL}$ dry benzene at $50^{\circ} \mathrm{C}$ in a closed schlenk flask for $20 \mathrm{~h}$, stopped the reaction and solvent was evaporated under vacuum using a condenser bridge connected to a cooling trap. The resulting red solid was purified and crystallized by making a saturated solution of this solid in dry dichloromethane layered with n-hexane and by slow cooling up to $-18^{\circ} \mathrm{C}$ for 3 days. The resulting solid was then isolated by filtration under nitrogen, washed with $n$-hexane and dried in vacuum. Single crystal was obtained by again dissolving small quantity of this solid in dry dichloromethane layered with n-hexane, followed by slow cooling up to $-18^{\circ} \mathrm{C}$ for one week.

\section{Carbonylnitrosyl( $\pi$-allyl)triphenylphosphine iron complex} (1).

IR, $v / \mathrm{cm}^{-1}: 1916$ (CO), 1685 (NO).

${ }_{1 \mathrm{H}}$ NMR (500 MHz, d acetone, $\left.\delta \mathrm{ppm}\right): 7.46-7.53(\mathrm{~m}$, $15 \mathrm{H})$; $3.80-3.95(m, 1 \mathrm{H}) ; 3.63(d d, J=6.0,2.6 \mathrm{~Hz}, 1 \mathrm{H})$; $3.07(d, J=12.3 \mathrm{~Hz}, 1 \mathrm{H}) ; 2.98(t, J=7.9 \mathrm{~Hz}, 1 \mathrm{H}) ; 2.79-3.0$ $(m, 1 \mathrm{H})$.

${ }^{13} \mathrm{C}$ NMR ( $125.7 \mathrm{MHz}$, d acetone, $\delta \mathrm{ppm}$ ): 223.83 ( $d$, J cp $=22.05 \mathrm{~Hz}, \mathrm{CO}) ; 136.3,135.9,133.8,133.7,131.25,131.23$, 129.5, 129.4 (Ar-C); 94.75 (central-C); $59.0\left(=\mathrm{CH}_{2}\right)$.

*email: imran_inorganic@yahoo.com; ktm7ro@yahoo.com, Phone: 0040/725160304 


\begin{tabular}{|c|c|c|c|}
\hline Complex & (1) & (2) & \\
\hline Formula & $\mathrm{C}_{22} \mathrm{H}_{20} \mathrm{FeNO}_{2} \mathrm{P}$ & $\mathrm{C}_{23} \mathrm{H}_{22} \mathrm{FeNO}_{2} \mathrm{P}$ & \\
\hline Formula weight & 417.21 & 431.24 & \\
\hline Color & Dark red & Orange & \\
\hline Temperature $\mathrm{T} / \mathrm{K}$ & $293(2) \mathrm{K}$ & $293(2) \mathrm{K}$ & \\
\hline Wavelength $\mathrm{NA}$ & $0.71073^{-1}$ & 0.71073 & \\
\hline Crystal System & Triclinic & Orthorhombic & \\
\hline Space group & P-1 & Pbca & \\
\hline a) & $9.3322(7)$ & $15.684(3)$ & \\
\hline $\mathrm{b} / \mathrm{A}$ & $10.4512(7)^{-}$ & $15.582(3)$ & \\
\hline $\mathrm{c} / \mathrm{A}$ & $10.6202(9)$ & $16.867(4)$ & \\
\hline Alpha $(\alpha)$ deg & $78.484(4)$ & 90 & \\
\hline Beta $(\beta) / \operatorname{deg}$ & $85.256(4)$ & 90 & Table 1 \\
\hline Gamma ( $\gamma) /$ deg & $79.280(4)$ & 90 & X-RAY \\
\hline Volume $\left(\mathrm{V} / \mathrm{A}^{3}\right)$ & $996.13(13)$ & $4122.0(15)$ & CRYSTALLOGRAPHIC \\
\hline Z & 2 & 8 & DATA FOR \\
\hline Calculated density $\left(\mathrm{dmg}^{-3}\right)^{-}$ & $1.391^{-}$ & 1.390 & COMPOUNDS (1) \\
\hline Absorption coefficient $/ \mathrm{mm}^{-1}$ & 0.853 & 0.827 & \\
\hline$F(000)$ & 432 & 1792 & \\
\hline Crystal size $/ \mathrm{mm}$ & $0.1 \times 0.05 \times 0.05$ & $0.7 \times 0.25 \times 0.03^{-}$ & \\
\hline $\begin{array}{l}\text { Theta range for data collection } \\
(\theta / \mathrm{deg})\end{array}$ & 7.86 to 25.00 & 2.20 to 24.00 & \\
\hline Limiting indices & $\begin{array}{c}-10<=\mathrm{h}<=11,-12<=\mathrm{k}<12,12<=1 \\
<12\end{array}$ & $\begin{array}{c}0<=\mathrm{h}<=17,0<=\mathrm{k}<17, \\
-19<=1<0\end{array}$ & \\
\hline Reflections collected unique & $5851 / 3356$ & $3231 / 3231$ & \\
\hline$R$ (int.) & 0.0969 & $0.0000^{-}$ & \\
\hline Completeness to theta $=24.00$ & $95.9 \%$ & $99.8 \%$ & \\
\hline Refinement method & Full-matrix least squares on $\mathrm{F}^{2}$ & Full-matrix least squares on $\mathrm{F}^{2}$ & \\
\hline Data-restrains/parameters & $3356 / 6 / 254$ & $3231 / 0 / 254$ & \\
\hline Goodness-of-fit on $\mathrm{F}^{2}$ & $1.088^{-1096}$ & $1.070^{-}$ & \\
\hline Final $R$ indices $[1>2$ sigma(1)] & $\mathrm{R} 1=0.0839, \mathrm{wR} 2=0.1685^{\circ}$ & $\mathrm{R} 1=0.1006, \mathrm{wR} 2=0.1442$ & \\
\hline$R$ indices (all data) & $\mathrm{R} 1=0.1459, \mathrm{wR} 2=0.1875$ & $\mathrm{R} 1=0.2352, \mathrm{wR} 2=0.1728$ & \\
\hline Extinction coefficient & $0.003(7)^{-}$ & $0.00007(9)$ & \\
\hline Largest diff. peak and hole & 0.530 and $-0.565 \mathrm{e}^{-\mathrm{A}^{-3}}$ & 0.719 and $-0.408 \mathrm{e} \cdot \mathrm{A}^{-5}$ & \\
\hline
\end{tabular}

ESI/MS: (El, $70 \mathrm{eV}), \mathrm{m} / \mathrm{z}(\%): 389$ (100) [M+-CO]; 359 (46) [ $\mathrm{M}^{+}-$-CO-NO]; 348 (23) $\left[\mathrm{M}^{+}-\mathrm{CO}^{-} \mathrm{C}_{3} \mathrm{H}_{5}\right] ; 262$ (35) [PPh] ; 239 (38), 183 (53).

HRMS: Calculated, 417.0581; Found, 417.0575.

Preparation of (2-methyl- $\pi$-allyl)carbonylnitrosyltriphenylphosphine iron (2).

This complex was synthesized by the same procedure as adopted above for complex (1) by reacting a mixture of (2-methyl- $\pi$-allyl) dicarbonylnitrosyl iron complex $(0.394 \mathrm{~g}$, $2.0 \mathrm{mmol}$ ) and triphenylphosphine $(0.524 \mathrm{~g}, 2.0 \mathrm{mmol})$. However, the resulting residuet was column chromatographed on silica gel using petroleum ether and dichloromethane (3:1) as eluent, the first fraction was starting material followed by complex (2). Solvent was then evaporated and the resulting orange solid was crystallized from a saturated solution of this solid in dry dichloromethane layered with dry n-hexane as described for complex (1).

Carbonylnitrosyl(2-methyl- $\pi$-allyl)triphenylphosphine iron complex (2).

IR, v/cm-1: 1903 (CO), 1656 (NO).

${ }^{1} \mathrm{H}$ NMR (500 MHz, d acetone, $\left.\delta \mathrm{ppm}\right):$ 7.47-7.68 ( $\mathrm{m}$, $15 \mathrm{H}) ; 3.52-3.54$ (br-s, $1 \mathrm{H}) ; 3.13(\mathrm{~s}, 1 \mathrm{H}) ; 3.07-3.10$ (br-s, $1 \mathrm{H}) ; 2.75-2.80(\mathrm{br}-\mathrm{s}, 1 \mathrm{H}) ; 1.0(\mathrm{~s}, 3 \mathrm{H})$.

${ }^{13} \mathrm{C}$ NMR $\left(125.7 \mathrm{MHz}\right.$, $\mathrm{d}_{6}$ acetone, $\left.\delta \mathrm{ppm}\right): 222.56(d, J c p$ $=20.9 \mathrm{~Hz}, \mathrm{CO}) ; 136.9,136.5,133.99,133.90,131.23$, 131.21, 129.47, 129.39 (Ar-C); 112.7 (central-C); 62.0 $\left(=\mathrm{CH}_{2}\right) ; 22.07\left(\mathrm{CH}_{3}\right)$.

ESI)MS: (El, $70 \mathrm{eV}), \mathrm{m} / \mathrm{z}(\%): 403$ (100) [M+-CO]; 401 (8) $\left[\mathrm{M}^{+}-\mathrm{NO}\right] ; 373$ (41) [M+-CO-NO]; 348 (14) $\left[\mathrm{M}^{+}-\mathrm{CO}-\right.$

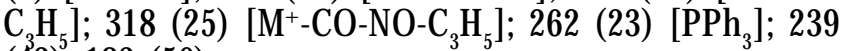
(42), $183(56)$.

HRMS: Calculated, 431.0738; Found, 431.0729.

\section{Results and discussions}

$\left(\eta^{3}\right.$-allyl) carbonylnitrosyltriphenylphosphine iron complexes were synthesized by ligand exchange reactions of $(\pi$-allyl) iron complexes with triphenylphosphine ligand. It was observed that during these reactions one of the carbonyl ligand was replaced by triphenylphosphine ligand as shown below.

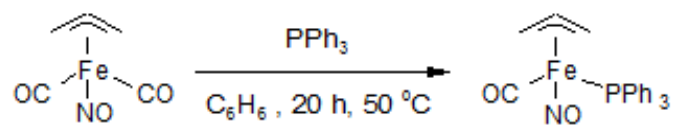

(1)

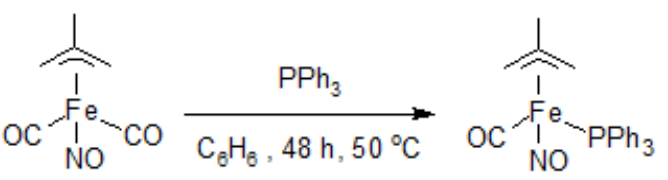

(2)

The synthesized complexes (1) and (2) were purified by suitable techniques and characterized by infrared, nuclear magnetic resonance spectroscopy, low resolution mass and high resolution mass spectrometry. Both the complexes (1) and (2) are colored solids (red, 1; orange, 2) and sensitive towards air and moisture, therefore all work up was carried out in an inert atmosphere.

IR spectra of complexes (1),(2)

The IR spectra of carbonylnitrosyl $\left(\eta^{3}\right.$-allyl)triphenylphosphine iron complexes (1), (2) show absorption bands in the range of $1917 \mathrm{~cm}^{-1}$ to $1902 \mathrm{~cm}^{\times 1}$ and $1655 \mathrm{~cm}^{-1}$ to $1686 \mathrm{~cm}^{\times 1}$ which can be assigned to carbonyl stretching and nitrosyl stretching respectively [10]. 
NMR studies and Mass spectrometry

${ }^{1} \mathrm{H}$ NMR spectra of complexes (1),(2)

The ${ }^{1} \mathrm{H}$ NMR spectrum of carbonylnitrosyl $\left(c^{3}\right.$ allyl)triphenylphosphine iron complex (1) was recorded in $\mathrm{d}$-acetone at ambient temperature and is represented in (Fig. 1a). This shows a multiplet signal in the aromatic region integrating to $15 \mathrm{H}$ and can be assigned to 15 protons of triphenylphosphine ligand. However, the allylic part of this spectrum is quite complicated, it is difficult to assign five different signals for five allylic protons in this region. It may reveal either the presence of dynamic phenomenon or asymmetry of protons due to partial localization of the double bond. This complex (1) in solid state structure, exists in two isomeric forms, exo and endo as revealed by single crystal XRD studies (Fig. 4). It is therefore can safely be assumed that in solution, there might be the fast interconversion of exo in endo isomer rendering the assignment of the chemical shift to specific protons difficult. Furthermore, in exo-isomer, there is strong difference in C$\mathrm{C}$ bond lengths ( $1.21 \AA$ vs $1.60 \AA$ ) which points into the direction of one $\mathrm{C}-\mathrm{C}$ bond of allylic ligand possessing more of an olefinic character.

In ${ }^{1} \mathrm{H}$ NMR spectrum of carbonylnitrosyl(2-methyl- $\pi$ allyl)triphenylphosphine iron complex (2), also show a multiplet at 7.47-7.68 ppm and can be assigned to triphenyl phosphine ligand (Fig. 1b). Solution NMR studies of gold complexes containing triphenyphosphine as ligand shows same chemical shift for phosphine ligand [11, 12].

A singlet at $\delta 1.0 \mathrm{ppm}$ is assigned to protons of methyl group. Four signals in the form of singlets and broad singlets from $2.80 \mathrm{ppm}$ to $3.54 \mathrm{ppm}$ can be assigned to four allylic protons resembles to the literature [13]. The presence of four signals for allylic protons indicate either the presence of dynamic phenomenon or asymmetry of protons due to partial localization of double bond similar to that of complex (1).

${ }^{13} \mathrm{C}$ NMR spectra of complexes (1),(2)

In the ${ }^{13} \mathrm{C}$ NMR spectrum of complex (1) (Fig. 2a), a doublet appears at $\delta 223.83 \mathrm{ppm}$ with a coupling constant $J \mathrm{cp}=22.05 \mathrm{~Hz}$ and can be attributed to carbonyl carbon . This doublet is due to the coupling of phosphorous of triphenylphosphine with the carbonyl carbon. A set of signal which appear in the range from $\delta 136.3 \mathrm{ppm}$ to $\delta 129.4$ ppm can be assigned to aromatic carbons of triphenylphosphine ligand. Similar assignment for carbon atoms of triphenylphosphine ligand has been reported in the literature [11]. The central carbon of allyl moiety appears at $\delta 94.75 \mathrm{ppm}$. A signal at $\delta 59.0 \mathrm{ppm}$ integrating to two carbons was assigned to the two terminal carbon atoms of allyl moiety. In the ${ }^{13} \mathrm{C}$ NMR spectrum of complex(2)(Fig. 2b), a doublet appears at $\delta 222.56 \mathrm{ppm}$ with a coupling constant $/ \mathrm{cp}=20.9 \mathrm{~Hz}$ which was assigned to carbonyl carbon. A set of signal in the range from $\delta$ $136.9 \mathrm{ppm}$ to $\delta 129.39 \mathrm{ppm}$ belongs to the aromatic carbons of triphenylphosphine ligand. The central carbon of allyl moiety appears at $\delta 112.7 \mathrm{ppm}$ while a signal at $\delta$ $62.0 \mathrm{ppm}$ integrating to the two carbons can be assigned to the two terminal carbons of allyl moiety. Approximately similar chemical shift values for the allylic carbons have been reported in literature $[10,13,14]$. Another signal at $\delta$ $22.02 \mathrm{ppm}$ can be attributed to methyl carbon also describe in literature $[10,14]$.

ESI/Mass spectra of complexes (1),(2)

The ESI/Mass spectra of both carbonylnitrosyl $\left(\eta^{3}\right.$ allyl)triphenylphosphine iron complexes (1), (2) indicate the presence of parent ion and fragmentation due to

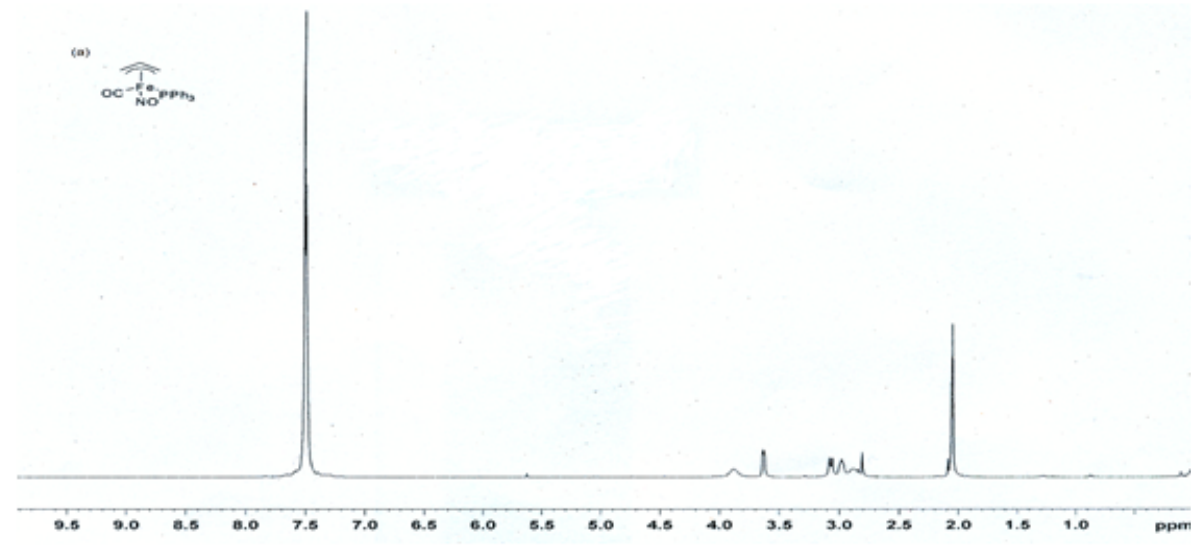

(a)

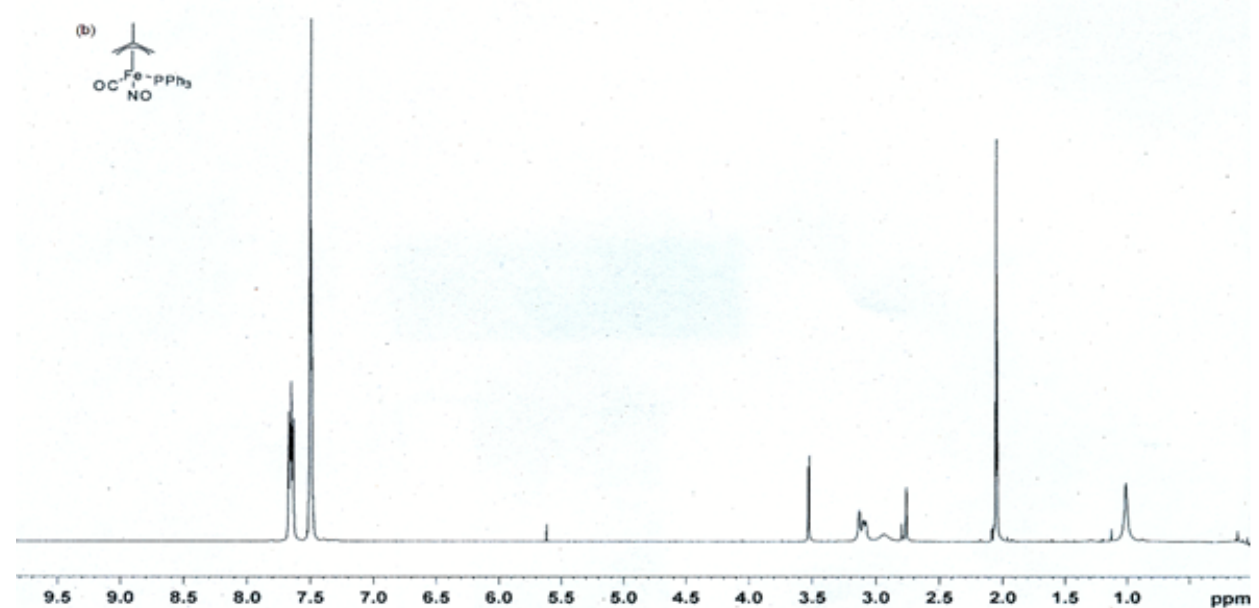

(b)
Fig. 1. 'H NMR spectra of complexes; (a)Carbonylnitrosyl( $\pi$-allyl) triphenylphosphine iron(1);

(b) Carbonylnitrosyl(2-methyl- $\pi$ allyl) triphenylphosphine iron (2) 


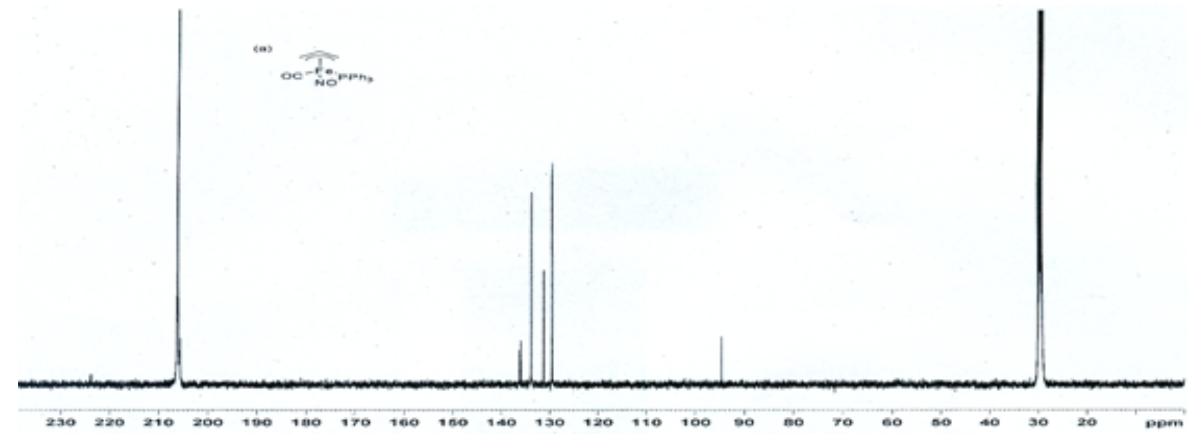

(a)

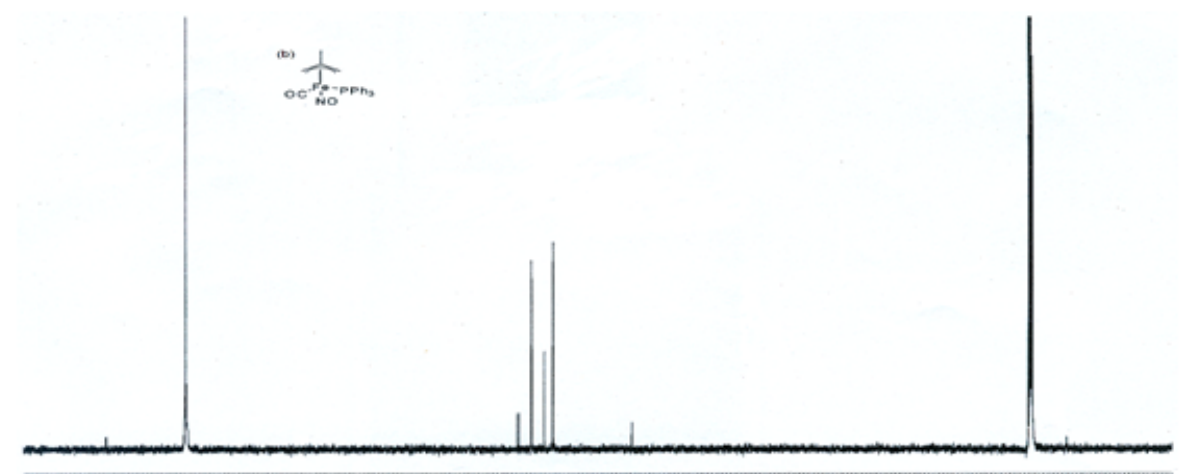

(b)

successive loss of carbonyl, nitrosyl and allyl ligands (Fig. $3 a$, Fig. 3b). Base peak at $m / z 389$ for complex (1) and at $\mathrm{m} / \mathrm{z} 403$ for complex (2) is due to the loss of carbonyl

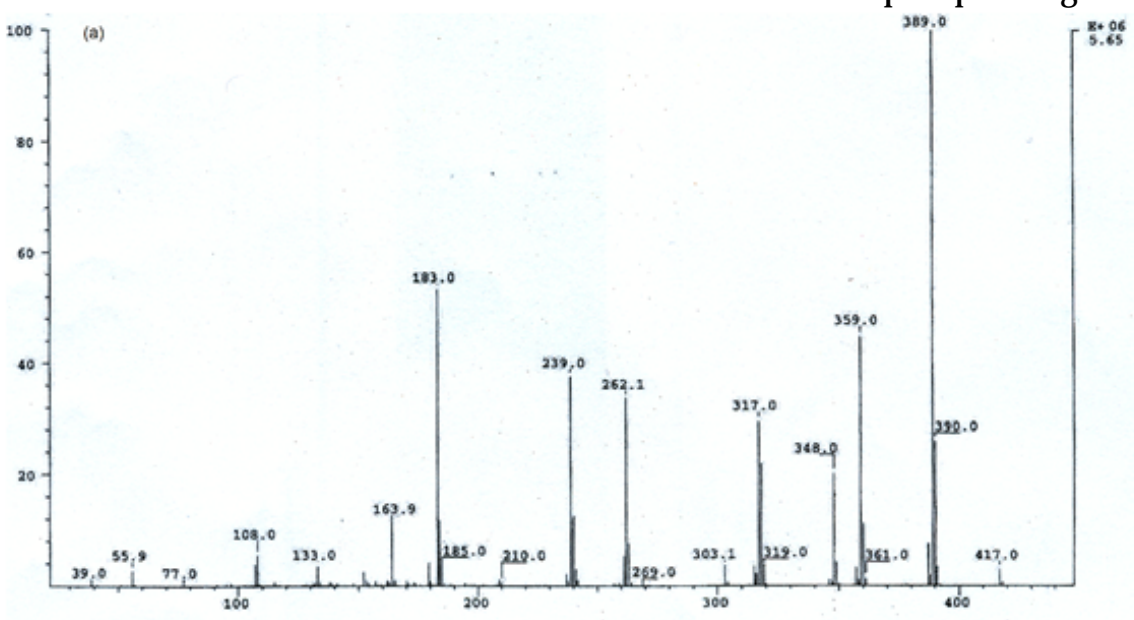

(a)

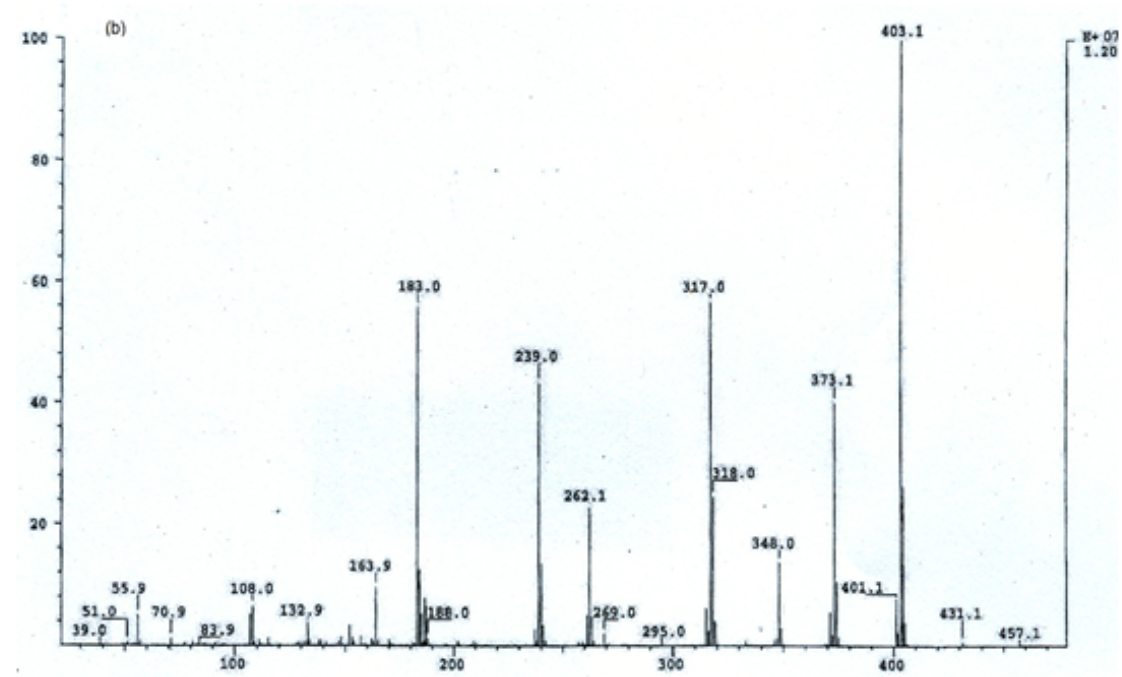

(b) ligand from these complexes. This reveals that carbonyl ligand can be readily exchanged. In both spectra, no peak was observed due to loss of only triphenylphosphine ligand indicating strong sigma $(\sigma)$ donor ability of triphenylphosphine ligand.
Fig. 2. ${ }^{13} \mathrm{C}$ NMR spectra of complexes;(a)Carbonylnitrosyl $(\pi$ allyl)triphenylphosphine iron(1) (b) Carbonylnitrosyl(2methyl- $\pi$-allyl) triphenylphosphine iron (2)
Fig. 3. Mass spectra of complexes; (a) Carbonylnitrosyl $(\pi$ allyl)triphenylphosphine iron (1);

(b) Carbonylnitrosyl (2-methyl- $\pi$ allyl) triphenylphosphine iron (2) 


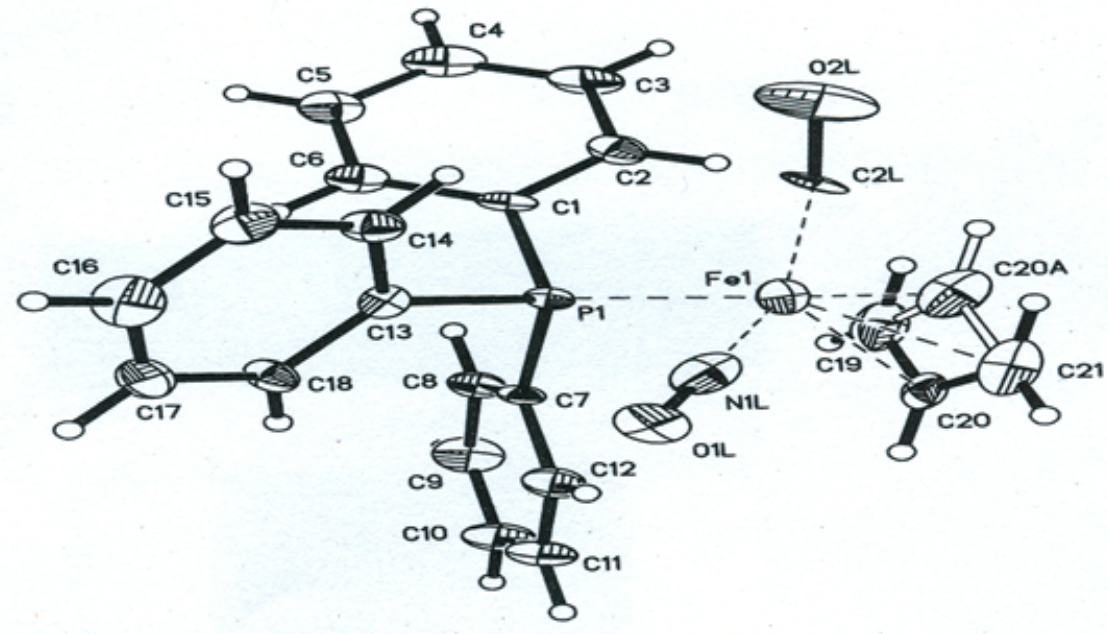

Fig. 4. X-Ray crystal structure of ( $\pi$ allyl) $\mathrm{Fe}\left(\mathrm{PPh}_{3}\right)(\mathrm{CO})(\mathrm{NO})$ (1)

Solid state structure

X-Ray crystallography

The molecular structure of the both the complexes (1) and (2) were established from X-ray crystallography and are shown in (Fig. 4) and (Fig. 5) respectively. Both the complexes are monomeric with coordination 6 and possess distorted octahedral geometry. Coordination environment around iron in each complex by a phosphorous (from triphenylphosphine), a nitrogen (from nitrosyl), four carbons (from a carbonyl and allyl ligand).

The crystal structure of complex (1) (Fig. 4) has certain remarkable features. Important bond lengths and angles are given in (table 2). For instance, metal center is coordinated in a distorted octahedral configuration similar to the prior observation by Mattern [15] and Nakanishi [7]. The Fe-N-O angle of $176.8^{\circ}$ points into the direction of a cationic ligand bound end-on to the metal, hence, stabilizing the high electron density which is exposed on the metal center. The allyl ligand is coordinated in a $\eta^{3}$ mode with the two $\mathrm{Fe}-\mathrm{C}$ bonds i.e. Fe-C19 and Fe-C21 (2.148 $\AA$ vs $2.118 \AA$ ). However, due to the position of the nitrosyl ligand the allyl moiety might be oriented in either an exo (NO points away from the allyl ligand) or endo (NO is located under the allyl ligand). Therefore, it allows a comparison of bond length and angles in both endo and exo-diastereoisomers. The relative population of endo-exo in the solid state structure is approximately 4:1. Because of the orientation of the nitrosyl ligand, a significantchange in the bond length Fe-C2O is noted.The Fe-C2O in case of endo is $2.092 \AA$ which is $1.770 \AA$ (Fe-C20) in case of exoadduct. Similarly, the C19-C20 and the C20-C21 bond lengths are significantly different. In endo-adductC-C bonds are of nearly a similar length $(1.344 \AA$ vs. $1.405 \AA)$ indicating a fast isomerization of the $\pi$-bond. However, in the exoadduct, there is a strong difference in the bond lengths $(1.210 \AA$ vs. $1.600 \AA)$, which points into the direction of one $\mathrm{C}-\mathrm{C}$ bond possessing more of an olefinic character.

The crystal structure of complex (2) is shown in two different projections in (Fig. 5). Important bond lengths and angles are given in (table 3 ). In this complex, the central allylic carbon atom (C20) is closer to iron at $2.070 \AA$ than the two terminal carbon atoms Fe-C19 (2.129 $\AA$ ) and FeC21 (2.145 $\AA$ ). The allylic angle (C19-C20-C21) is $117.3^{\circ}$. Furthermore, the bond lengths of the two terminal carbon from the central carbon are nearly identical, C19-C20 (1.372 $\AA)$ and C20-C21 (1.472 $\AA$ ) respectively. The bond distances from the metal atom to the two terminal carbon (C19 and C21) of the allyl moiety are nearly equal ( $2.129 \AA$ and 2.145 $\AA)$. Similarly, C-C bond lengths (C19-C20 = 1.372 $\AA, C 20-$
SELECTED BOND LENGTHS [ $\AA$ ] AND ANGLES [DEG] OF COMPOUND (1)

\begin{tabular}{|c|c|c|c|}
\hline \multicolumn{2}{|c|}{ Bond Length $[\mathrm{A}]$} & \multicolumn{2}{|c|}{ Bond Angle [Deg ( $\left.\left.{ }^{\circ}\right)\right]$} \\
\hline $\mathrm{Fe}-\mathrm{Pl}$ & 2.225 & $\mathrm{Pl}-\mathrm{Fe}-\mathrm{N}$ & 89.2 \\
\hline $\mathrm{Fe}-\mathrm{Nl}$ & 1.777 & $\mathrm{P} 1-\mathrm{Fe}-\mathrm{C}_{2}$ & 105.2 \\
\hline $\mathrm{Fe}-\mathrm{C} 2$ & 1.664 & $\mathrm{Pl}-\mathrm{Fe}-\mathrm{C} 19$ & 89.0 \\
\hline $\mathrm{Fe}-\mathrm{C} 19^{-}$ & 2.148 & $\mathrm{Pl}-\mathrm{Fe}-\mathrm{C}_{20}$ & 108.4 \\
\hline $\mathrm{Fe}-\mathrm{C} 20^{\circ}$ & 2.092 & $\mathrm{P} 1-\mathrm{Fe}-\mathrm{C} 20 \mathrm{~A}$ & 120.9 \\
\hline $\mathrm{Fe}-\mathrm{C} 20 \mathrm{~A}$ & 1.770 & $\mathrm{P} 1-\mathrm{Fe}-\mathrm{C} 21$ & 145.9 \\
\hline $\mathrm{Fe}-\mathrm{C} 21^{-}$ & 2.118 & $\mathrm{Fe}-\mathrm{N1}-\mathrm{O}^{-}$ & 176.8 \\
\hline $\mathrm{C} 19-\mathrm{C}_{20} \mathrm{O}^{--}$ & 1.344 & $\mathrm{Fe}-\mathrm{C} 2-\mathrm{O}^{-}$ & 167.8 \\
\hline $\mathrm{C} 19-\mathrm{C} 20 \mathrm{~A}$ & 1.210 & $\mathrm{C} 19-\mathrm{Fe}-\mathrm{C} 2$ & 111.6 \\
\hline $\mathrm{C} 20-\mathrm{C}_{2} \mathrm{I}^{-}$ & 1.405 & $\mathrm{Cl9}-\mathrm{Fe}-\mathrm{N1}$ & 132.2 \\
\hline $\mathrm{C} 20 \mathrm{~A}-\mathrm{C} 21$ & 1.600 & $\mathrm{C} 20-\mathrm{Fe}-\mathrm{C} 2$ & 131.3 \\
\hline & & $\mathrm{C} 20 \mathrm{~A}-\mathrm{Fe}-\mathrm{C} 2$ & 89.8 \\
\hline & & $\mathrm{C} 21-\mathrm{Fe}-\mathrm{C} 2$ & 106.5 \\
\hline & & $\mathrm{C} 21-\mathrm{Fe}-\mathrm{N1}$ & 88.8 \\
\hline & & $\mathrm{C} 19-\mathrm{C} 20-\mathrm{C} 21$ & 120.1 \\
\hline & & $\mathrm{C} 19-\mathrm{C} 20 \mathrm{~A}-\mathrm{C} 21$ & 115.0 \\
\hline
\end{tabular}

Table 3

SELECTED BOND LENGTHS [ $\AA$ ] AND ANGLES [DEG] OF COMPOUND (2)

\begin{tabular}{|c|c|c|c|}
\hline \multicolumn{2}{|c|}{ Bond Length $[A]$} & \multicolumn{2}{|c|}{ Bond Angle [Deg ( $)$ ] } \\
\hline $\mathrm{Fe}-\mathrm{Pl}$ & 2.228 & $\mathrm{P} 1-\mathrm{Fe}-\mathrm{N1}$ & 1059 \\
\hline $\mathrm{Fe}-\mathrm{N1}$ & 1.628 & $\mathrm{P} 1-\mathrm{Fe}-\mathrm{C} 2$ & 90.2 \\
\hline $\mathrm{Fe}-\mathrm{C} 2$ & 1.714 & $\mathrm{P} 1-\mathrm{Fe}-\mathrm{C} 19$ & 149.1 \\
\hline $\mathrm{Fe}-\mathrm{C19}$ & 2.120 & $\mathrm{P} 1-\mathrm{Fe}-\mathrm{C} 20^{\circ}$ & 111.7 \\
\hline $\mathrm{Fe}-\mathrm{C} 20^{-}$ & 2.070 & $\mathrm{P} 1-\mathrm{Fe}-\mathrm{C} 21$ & 89.6 \\
\hline $\mathrm{Fe}-\mathrm{C} 21^{-1}$ & 2.145 & $\mathrm{Fe}-\mathrm{N} 1-\mathrm{O}$ & 166.8 \\
\hline $\mathrm{C} 19-\mathrm{C} 20^{-}$ & 1.372 & $\mathrm{Fe}-\mathrm{C} 2-\mathrm{O}$ & 176.3 \\
\hline $\mathrm{C} 20-\mathrm{C} 21$ & 1.472 & $\mathrm{C} 19-\mathrm{Fe}-\mathrm{C} 2$ & 85.6 \\
\hline $\mathrm{C} 20-\mathrm{C} 22$ & 1.532 & $\mathrm{Cl9}-\mathrm{Fe}-\mathrm{N1}$ & 103.7 \\
\hline & & $\mathrm{C} 20-\mathrm{Fe}-\mathrm{C} 2$ & 92.0 \\
\hline & & $\mathrm{C} 20-\mathrm{Fe}-\mathrm{N1}$ & 133.5 \\
\hline & & $\mathrm{C} 21-\mathrm{Fe}-\mathrm{C} 2$ & 127.4 \\
\hline & & $\mathrm{C} 21-\mathrm{Fe}-\mathrm{N1}$ & 115.9 \\
\hline & & $\mathrm{C} 19-\mathrm{Fe}-\mathrm{C} 20^{-}$ & 38.2 \\
\hline & & $\mathrm{C} 19-\mathrm{C} 20-\mathrm{C} 21$ & 117.3 \\
\hline & & $\mathrm{C} 20-\mathrm{Fe}-\mathrm{C} 21^{-}$ & 69.4 \\
\hline & & $\mathrm{C} 19-\mathrm{C} 20-\mathrm{C} 22$ & 117.9 \\
\hline & & $\mathrm{C} 21-\mathrm{C} 20-\mathrm{C} 22$ & 124.7 \\
\hline
\end{tabular}

$\mathrm{C} 21=1.472 \AA$ ) in the allyl ligand which are nearly similar indicates a $\pi$-coordination of the allyl ligand to the metal center. However, due to the position of the nitrosyl ligand, the allyl moiety might be oriented in either an exo (NO points away from allyl ligand) or endo (NO is located under the allyl ligand) as described above for complex (1). The crystal structure of this complex (2) however indicates an endo-isomer because NO is located under the allyl ligand. The Fe-CO and Fe-NO angles have been found to be nearly linear (176.3 $3^{\circ}$ and $166.8^{\circ}$ respectively). 

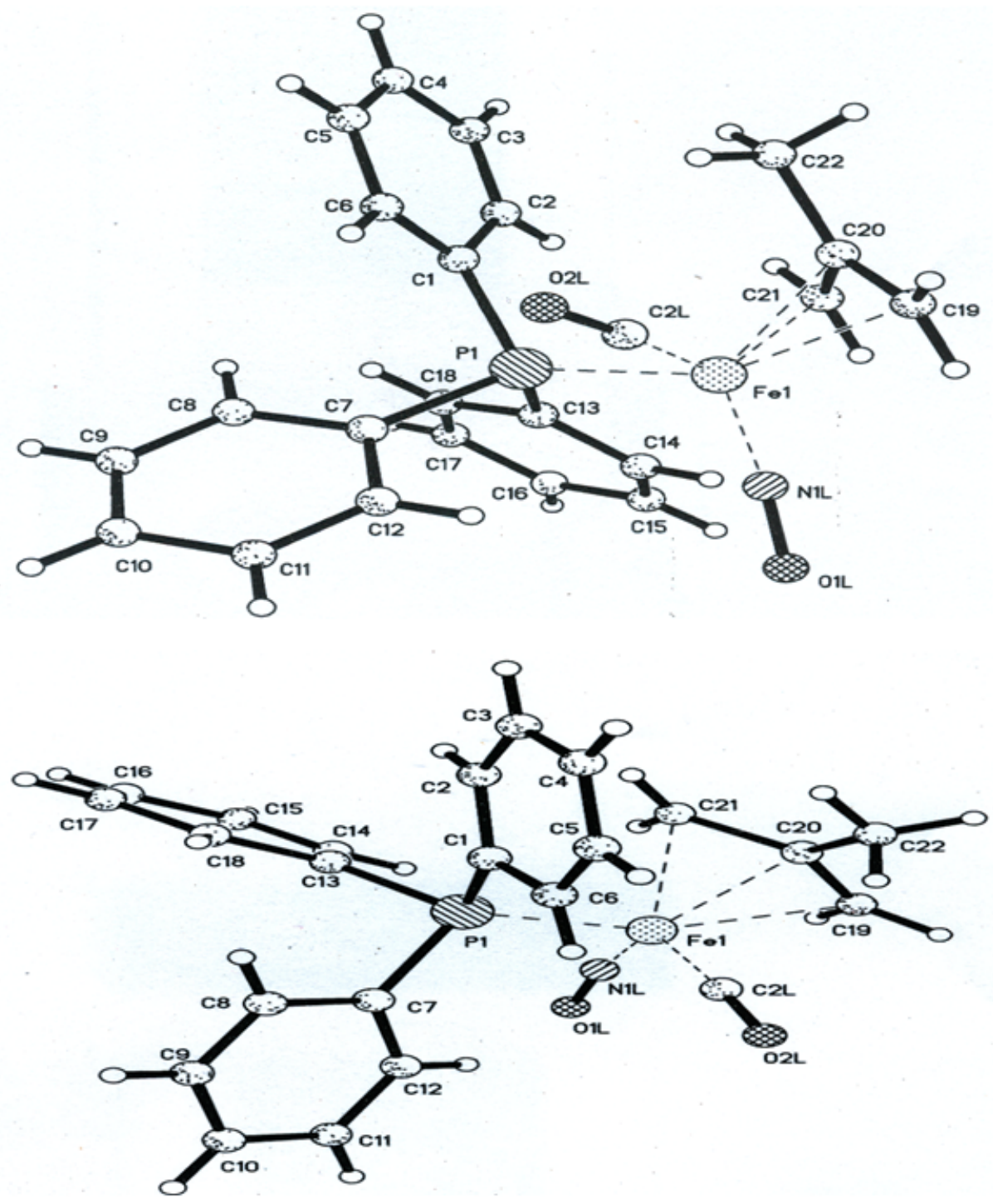

Fig. 5. Two projections for X-Ray crystal structure of (2-methyl- $\delta$ allyl) $\mathrm{Fe}\left(\mathrm{PPh}_{3}\right)(\mathrm{CO})(\mathrm{NO})(2)$

\section{Conclusions}

Two novel ( $\eta^{3}$-allyl)carbonylnitrosylphosphine iron complexes i.e. ( $\pi$-allyl)carbonyl nitrosyltriphenylphosphine iron (1) and (2-methyl- $\pi$-allyl)carbonylnitrosyltriphenylphosphine iron (2) have been isolated and well characterized. Geometry of iron in both complexes was found to be distorted octahedral. Moreover, another important phenomenon of an endo- and exodiastereoisomerism has been identified in these complexes and described.

Acknowledgement: Miss. Misbah Tabassam highly acknowledges the support of Stuttgart University, Germany, for their help in characterization of these complexes.

\section{References}

1.COLLMAN, J.P., Principles and applications of organotransition metal chemistry, University Science Books, 1987

2.ENDERS, D., JANDELEIT, B., VON BERG, S., Synlett, 1, 1997, p. 421 3.ENDERS, D., JANDELEIT, B., VON BERG, S., RAABE, G., RUNSINK, J., Organometallics, 20, 2001, p. 4312

4.LEY, S.V., COX, L.R., MEEK, G., Chem.Rev., 96, 1996, p. 423
5.ELLER, M., BOLM, C., (eds.), Transition metals for organic synthesis, (Wiley-VCH Verlag GmbH, Weinheim, Germany) 2004 6.CHAUDHARI, F.M., KNOX, G.R., PAUSON, P.L., J .Chem.Soc.C:Organic, 1967 , p. 2255

7.NAKANISHI, S., MEMITA, S., TAKATA, T., ITOH, K., Bull.Chem.Soc.Jpn., 71, 1998, p. 403

8NAKANISHI, S., YAMAGUCHI, H., OKAMOTO, K., TAKATA, T., Tetrahed.Asym., 7, 1996, p. 2219

9.CARDACl, G., Inorg.Chem., 13, 1974, p. 2974

10.TABASSAM, M., MEHMOOD, Z., GILLANI, S.R., IMRAN, M., Synth.React.Inorg. Metal-Org.Nano-Met.Chem., 41, 2011, p. 805

11.GANADU, M.L., NALDINI, L., CRISPONI, G., NURCHI, V., Spectrochim.Acta Part A Mol.Spectrosc., 47, 1991, p. 615

12.SHARMA, R., HOLLAND, G.P., SOLOMON, V.C., ZIMMERMANN, H., SCHIFFENHAUS, S., AMIN, S.A., BUTTRY, D.A., YARGER, J.L., J.Phys.Chem.C, 113, 2009, p. 16387

13. HEGEDUS, L.S., AAKERMARK, B., OLSEN, D.J., ANDERSON, O.P., ZETTERBERG, K., J.Am.Chem.Soc., 104, 1982, p. 697

14.BRASSAT, I., KEIM, W., KILLAT, S., MÖTHRATH, M., MASTRORILLI, P., NOBILE, C.F., SURANNA, G.P., J.Mol.Catal.A Chem., 157, 2000, p. 41

15.EBERHARDT, U., MATTERN, G., Chem.Ber., 121, 1988, p. 1531

Manuscript received: 4.06 .2018 